DR STEVEN RATUVA is a senior lecturer at the University of Auckland's Centre for Pacific Studies.

\section{Critical Fiji media studies defy climate of censorship}

Media and Democracy in Fiji, edited by Shailendra Singh and Biman Prasad. Suva: Fijian Studies: A Journal of Contemporary Fiji (2008/9). 6 (Nos. 1 and 2). 298 pp. ISSN 1728-7456

$\mathrm{T}$ HE SPECIAL edition on 'Media and Democracy in Fiji' of Fijian Studies: A Journal of Contemporary Fiji is an engaging collection of articles of diverse quality presented in varying degrees of intellectual temperaments, some with political passion and unrestrained emotion, some with journalistic vigour and some with serious scholastic zeal. A few articles are outstanding in terms of analytical depth and cutting edge approach while some are lacklustre and lack what it takes to be a journal article. Nevertheless, the intensity of discourse relating to the media in Fiji and the Pacific is enough to

\section{Fijian Studies}

\section{A Journal of Contemporary Fiji}

Special Edition: Media \& Development in Fiji

Volume 6, Nos. 1 \& $2 \quad$ May \& November 2008

Articles

Coups, Media and Democracy in Fiji

Reproducing Disengagement: Citizens' Reproducing Disengagement: Citizens'
Orientations, the News Media, and Democracy in
Fiji

Media and Democracy in Fill: An Assessment of the Print Media's Coverage of the Office of the Auditor General

Freedom of the Gatekeepers: A Free Media Study of $\mathrm{NZ}$ and Fij - Self-Regulation or State

Women, the Press, and the Fiji Coups d'etat

Journalism in the New Age of Participation: Meeting the Challenge in Fiji Newsrooms

Sites of Resistance: Fijl's Untamed Media

Bridging the Divide with Participatory Video

Pacific Islands Diaspora Media: Conceptual and

Methodological Considerations for a Pilot Study

Freedom of Information and Media Accountability

in the Pacific: Case Studies of Fiji, Cook Islands

and Papua New Guinea

Shailendra Singh

Biman Prasad

Erik Larson

Susan Naisara Grey Graham Hassall

David Robie

Rae Nicholl

Sophie Foster

Hannah Harborow

Usha Sundar Harris

Evangelia Papoutsak

Naomi Strickland

Carolyn Thomas

Carly Tawhiao

Publisned by Fiji Institute of Applied Studies

inspire one's sense of appreciation of the role the media and journalists who operate in politically challenging environments like Fiji play. (The last such collection was 'crisis in coverage' published after the George Speight attempted coup, May, 2000).

However, one of the disappointments is that the journal does not live up to its promise of linking the media to 'development' as outlined by the cover title. None of the articles, including the introduction by the editors, has any direct bearing on the relationship between media and development, and one is supposed to make indirect and subtle connections here and there. (According to the 
inside title page, the theme is actually 'Media and Democracy'-Editor).

The article by Erik Larson of Macalester College (US) on the impact of the media on citizen's orientation provides a comprehensive analysis of the interface between the public realm of the media and private domain of the individual political discourse. This is based on his Fiji fieldwork and his argument is that one's professional disposition may shape one's propensity to be influenced by the media in everyday engagement. This article could have been strengthened by doing a more comprehensive sociological and cultural theory analysis of the episteme and cognitive processes of news reception, processing and consumption which influence how people think. It would have also been better if the paper explained the reason why 'the predominant public orientation towards news media results in most citizens experiencing news as disconnected from their daily lives' (p. 9).

The next article by Susan Grey and Graham Hassall on the media coverage of the Office of the Auditor General, deals with a very important issue of transparency and accountability. However, it fails to live up to expectations. The presentation is too dry, mechanical, lacks coherence and is devoid of in-depth critical analysis.
While it may pass as a satisfactory student paper, it unfortunately falls short of being in the league for a serious journal article, and especially unfortunate when the name of a senior academic is attached to it. This is one of the weaker articles in the issue.

David Robie of AUT University's Pacific Media Centre provides two well articulated articles, the first on media self-regulation and the second a retrospective on the high pressure role of journalists in Fiji-'coupcoup land'-in 2000. The first article examines the need to reconsider the often controversial subject of media accountability and self-regulation. The use of Bertrand's media accountability systems model provides a refreshing framework through which the media industry can re-examine itself in the context of a number of governance, ethical and logistical variables. Government after government in Fiji, whether catapulted into power by coups or by elections, have had a field day in media bashing. The media was the favourite scapegoat for policy failure, political controversy and even causing coups. Robie meticulously examines the question of how the media can reposition itself through self-assessment and self-reform without compromising its principles in an environment of ethno-political hostility. The second 
paper, originally published in 2001 after the George Speight coup, extends this further by looking at the multiple challenges faced by Fiji journalists who have to continually engage in tactical manoeuvring to avoid the waves of multi-frontal assaults from the government, political parties and other hostile groups. This is reinforced by an article on challenges in a multi-ethnic setting by Verenaisi Raicola. Padmini Gounder's paper takes issue with the media, especially the Fiji Times and how it would use the rhetoric of freedom of information as a tool for political manipulation, whether by explicit design or subtle overtones.

The attention (or lack of it) given to women by the media is often a concern because it reflects the parochially patriarchal nature of the dominant political and cultural media discourse, very much a reflection of the gender stratified culture of society at large. This is well articulated and analysed by Rae Nichol of Victoria University, Wellington. The political construction of women by the media helps reinforce and reproduce female subordination and there is a need to deconstruct and transform this as part of the emancipatory and enlightenment process for women as well as the media.

The dramatic popularity in cyberspace media is examined in an incisive way by Fiji Times deputy editor Sophie Foster. The shift in focus to virtual communication by the Fiji Times and other local media is a result of the global transformation of communication networking to facilitate the constant globalisation of the Fiji Diaspora. The Sotia Central blog set up by the Fiji Times has become a very popular virtual space for discussion, community networking and collective identity formation in a globalised world. The mushrooming of blogs over the years, has transformed the social and cultural terrain in a significant way. The public and private spaces converge as anonymous private individuals make their obscure thoughts public and global almost instantly in real time. Herein lies the future of the Pacific media.

This theme is taken up further by Hannah Harborow of the Secretariat of the Pacific Community who examines the role of blogs in the Fiji coup environment. She looks at the Intelligentsiya blog as a case study of 'sites of resistance' against the coup and the interim government (p. 129). About 40 or so blogs have emerged since the 2006 military coup and most have been dedicated to resistance against the coup while some are coup sympathisers and one or two consider themselves 'neutral'. The use of blogs ensures that participants have 
a politically safe space for dialogue, however, because of anonymity and difficulty in scrutiny, there is no accountability and often laws relating to defamation are readily undermined.

While it is a politically powerful weapon of democracy by the otherwise voiceless and subordinate, there are ethical issues involved if anonymity is abused. In the absence of a free media, blogging becomes a favourite mechanism for political resistance and this has provoked the fury of the interim government to take draconian steps to block and close down antigovernment blogs.

Perhaps an area which is often neglected in media literature is the use of participatory video, as presented by Usha Harris of Macquarie University. The article shows how the use of alternative media like video production helps empower women in rural areas and acts as a powerful medium for social transformation. The world of the rural poor, which were once isolated by geographical and social distance, are captured in pictures and made to come 'alive'. This has more impact on shaping the views of policy makers than technical development reports prepared by bureaucrats. Putting these videos online as in YouTube would no doubt make the isolated local experiences more global.

The article on Pacific Islands diaspora media by Evangelia Papoutsaki and Naomi Strickland, both of Unitec in Auckland, is a fascinating one because it reflects the importance of the media in adapting to the increasing geographical and social dispersal of Pacific peoples globally, as the New Zealand experience evidently shows. The diaspora Pacific media not only helps to magnify the Pacific voices, it also provides the heartbeat of communication and networking and acts as a socio-cultural fulcrum for shaping and reshaping new Pacific identities in an environment full of new cultural, socioeconomic and political challenges.

Media accountability should be an important feature of democracy as proposed by AUT graduate journalists Carolyn Thomas, Carly Tawhio and Natasha Burling as they do a comparative overview of issues of freedom of information and media accountability in Fiji, Cook Islands and Papua New Guinea. Although the article is purely descriptive, it provides a good overview of the existing mechanisms for oversight of media behaviour.

Daryl Tarte, the chair of the Fiji Media Council, takes the matter further by examining the role and history of the Fiji Media Council. Sophie Foster in her second article says that selfregulation is the best way forward for the Fiji media but first the Fiji Media 
Council needs substantive reform to make it more proactive and effective in dealing with media complaints.

Media freedom is not absolute but must be exercised within certain ethical, legal and cultural limitations. One way of enhancing the quality of the media is through what Richard Naidu, a radio journalist, refers to in his article as 'citizen journalism', meaning how citizens can be directly involved in the making, processing and dissemination of news.

Beyond the formal mechanisms of media accountability is the larger sociological issue of socio-cultural transformation. This is taken up by Kyle Anderson, a University of the South Pacific political scientist, who through a field project, attempted to identify the role of the media in forming and changing the political perception of citizens. She argues that the creation and reproduction of perception in this way leads to the formation of a 'new culture'. Although an ambiguous concept, it does remind us of the active role of the media in cultural transformation.

The papers in the Dialogue section are meant to create a debate atmosphere. Perhaps the most interesting is the debate or rather ferocious battle of words relating to Dr James Anthony's Report on 'Freedom and Independence of the Media in Fiji', commissioned by the Fiji Human Rights Commission, and the Media Council which provides a rebuttal of Anthony's insinuations. Dr Anthony's attempt to verbally obliterate the Fiji Media Council's credibility was vicious with overt racial overtones and in this issue, the Fiji Media Council unleashes salvo after salvo of criticism aimed at undermining the credibility of both Dr Anthony and his report.

This journal issue provides an interesting read for those interested in understanding the complex interplay between politics and the media in Fiji. It's a conglomeration of diverse minds talking of the same thing from different angles in the spirit of openness, ironically at a time when every word by journalists is thoroughly scrutinised by the government censors in 'Coup-coup land'.

\section{Reference}

Crisis and Coverage (2001). Special edition of Pacific Journalism Review. 7(1). 